https://doi.org/10.48009/1_iis_2009_225-231

\title{
SUCCESSFUL EFFORTS IN RECRUITING WOMEN INTO TECHNOLOGY COURSES - A CASE STUDY
}

Azad Ali, Indiana University of Pennsylvania, azad.ali@iup.edu

\begin{abstract}
This purpose of this paper is to describe efforts of recruiting women into computer technology courses. It illustrates the experience of one technology program in a university located in Western Pennsylvania and their successful efforts into recruiting women into a technology course. The Technology Support and Training (TST) program at Eberly College of Business (ECOBIT) Indiana University of Pennsylvania (IUP) teaches a technology capstone course for their students in a graduate program. This course was successful in attracting more female students to the course, and changing the perception of women enrolled in it about technology courses, thus the experience of this program is illustrated in this paper. The paper begin by describing the problem of low enrollment of women in technology courses, it gives reasons and suggest remedies for this problem. It then describes the experience of the TST department at IUP in recruiting women into their course.
\end{abstract}

Keywords: Women and technology programs, decline enrollment in computer programs, technology programs and women

\section{INTRODUCTION}

The decline of enrollment in technology programs has been puzzling administrators in different technology related academic programs. This trend had been going for a while and included many aspects of different technology programs. This decline is noticed especially among women. Recent years have showed a significant enrollment decline among female students in technology related programs. Different reasons have been attributed to this special decline and alternative solutions were suggested.
This paper adds to the discussion regarding the decline of women's enrollment in technology related courses. It focuses on efforts by a technology program at a university located in western Pennsylvania. Faculty members at the department of Technology Support and Training (TST) at Indiana University of Pennsylvania (IUP) have put efforts to recruit new students and especially women into their technology programs. The efforts ranged from a simple modification of course to content to larger efforts of program modification. These efforts were successful in at least one of the courses offered by the TST department, thus the experience of this department is illustrated in this paper.

The remainder of this paper is divided into four sections. The first section explains about the magnitude of this enrollment problem among women in technology programs. The second section discusses causes that are attributed to this problem. The third section suggests remedies for enrollment decline among women in technology related field. The last section summarizes the content of the paper and provides suggestions for future research regarding same topic.

\section{THE PROBLEM}

The main problem is that most female students do not consider any of the technology fields as their major. The number of female students represents a small percentage of the total students enrolled in technology courses. This number continues to decline as fewer and fewer women apply or enroll into technology related programs. Vilner and Zur 
[15] sums up the problem of women's enrollment in technology related courses:

When you sit in a Computer Science lecture at any university in the western world, what are the chances that the person sitting next to you will be a woman? Furthermore, what are the chances that the lecturer will be a woman? And if we were to enter a Computer Science classroom in a high school, what percentage of the students would be female? Computer Science is possibly one of the few remaining disciplines that is almost entirely controlled by men in the university staff, and in which the percentage of female students is usually below $30 \%$. This phenomenon is prevalent throughout the western world.

Enrollment of women in technology courses was never high. It has always been the case that men outnumber women in technology related programs. However, this small number of women in technology programs is dwindling further so that women constitute even a smaller portion of technology graduates. McDowell et al. [11] noted that

Women and minorities continue to be underrepresented in computer science, and the number of women pursuing college majors in this area is declining. In 1985, 37\% of computer science bachelor's degrees were awarded to women; in 2001 that percentage was down to $28 \%$ (p. 90).

This decreasing number of women in technology courses led to fewer graduate and also to fewer percentage of women in the workforce in technology related jobs. This means poor representation of women in the real world and having fewer role models of women in technology related workforce. Teague \& Roe [13] noted the following about this:

Women in IT are poorly represented at university which means there is less opportunity for support from female peers and possibly from role models in academic positions (p. 147).

Although fewer women are accepted into technology programs, the problem extends further into retention. Once they are accepted into the program, a higher percentage of women leave the program to pursue other majors. Vilner and Zur [15] noted that the dropout rate of domestic female students at their institution in 2004 was $36 \%$, compared to $23.5 \%$ for domestic male students.

Having this kind of low enrollment of women and then a higher rate of attrition may lead to thinking that the cause of such low enrollment is the lack of academic ability of women to complete such courses. However, data does not support this notion. To the contrary, it seems that academic ability has little to do with women's attraction and retention into computer programs. In a study conducted by Teague \& Roe [13 noted the following about women's ability and admission into computer programs:

Academic ability would seem to have little influence on women's attraction to and retention in programming courses. .....Women often perform well academically, yet perceive the programming environment as inhospitable, lacking social meaning and interaction which is incongruent with the real world. (p. 148)

Furthermore, the performance of women in technology programs does not seem that it below the performance of men in the same program. A study conducted to measure performance of women in these programs found out that once women get admitted into the program they do fine and have about the grade average as men [15].

Numerous statistics and studies support this opinion that fewer women are enrolled into technology related programs. Lenox, Woratschek and Davis [9] for example noted that while enrollment dropped in technology courses by about one $25 \%$, the decline of enrollment among women enrolled in technology programs dropped by $93 \%$ since the peak of women's enrollment in 1982.

Cantwell [3] explained that only $18 \%$ of the students represented from a particular computer science program were female which supports the concern of the shortage of women in computer related programs. 


\section{CAUSES AND REASONS}

A study conducted by Lenox, Woratscheck and Davis [9] to find the reasons that lead to the decline in enrollment in technology majors, attributed four common reasons for this enrollment decline: first, the image of technology courses as antisocial, second the cyclic nature of demand on technology professionals, third, increasing the different majors (like IT and MIS) and fourth the notion of outsourcing technology jobs overseas.

Another study carried on at Carnegie Mellon University, aimed at addressing the difficulty that women have with technology courses, concluded that men tend to view the computer as an object of study, while women tend to view the computer as a tool. The same study found that there were biases found in the previous admissions criteria and although prior programming experience was a requirement in the past, but was found to not be a predictor for success in the computer science major [2].

McDowell et al. [11] studied the phenomenon of gender difference of enrollment in technology courses and noted the following:

A number of variables have been proposed to account for this gender difference, including traditional socialization practices that reinforce math and science as male domains, lower confidence ratings and greater math anxiety among women, and women's tendency to take fewer advanced mathematics courses. The belief that computer science is a competitive, alienating field may further discourage women from pursuing careers in this area (p. 90).

Although the studies noted above agree that the decline of women's enrollment in technology programs need to be addressed at various levels, but the reasons that lead to this decline is not totally agreed on. Thus further examination of the factors that lead to decline of women's enrollment in technology program is warranted. The remainder of this section explains in further detail about some of the factors that led to the decline of women enrollment in technology programs. It covers these factors from pedagogical points and does not address other factors like admission criteria, market demand and math background.

\section{Difficulty Learning to Program}

It is well established among educators in the computer field that learning to program is a difficult to task to the majority of students [1] [8]. Different factors attributed to this difficulty including rigid syntax, unfamiliar structure and length of time spent to produce a simple output [1] [4]. But for women, the problem is deeply rooted in the perception of programming occupation and the way universities often introduce programming subjects into their curriculum[4] [5]. Teague \& Roe [13 noted the following this perception:

Programming is seen as a competitive occupation whose model student is the stereotypical 'geeky' young male, and this can lead initially to alienation, diminution of confidence and subsequent lack of interest for women (p. 148).

To complicate the problem further, different universities schedule beginner programming courses in the first year of enrollment, when the students are facing difficulty adjusting to new social environment. This first programming course often includes languages that use characters easily confused and make difficult to learn. This adds to the anxiety among the students and creates an environment that lead to dropping all out of the program.

\section{The problem of being asocial}

According to Liu [10], is that most real-world computer professionals deal with complex problems. Yet many computer courses do not involve projects of enough complexity to give students such experience.

Teague and Roe [13] noted that computer jobs in general are perceived as solitary occupations. This perception is fed by the notion that most computer jobs are conducted solely by one person where her/she sits in front of a terminal and spends hours upon hours trying to fix a single small problem they encounter. 
The academic environment may also lead to increase this perception especially in beginner courses. In some cases, the projects that are assigned to students are simple and do not give a perception of the real life problem. Often, these projects require the students to work alone and in cases require the students to follow numerous steps in order to achieve an output that does not related to real-world problems. Thus, these kind of projects may lead some students to feel isolated, alienated and deprived from realworld environment in computer technology and may lead many students (especially women) to drop out of the program.

\section{The issue of Competitive Environment}

According to Teague \& Roe[13]:

Programming is often perceived as a solitary occupation, one which is conducted in a competitive, rather than collaborative environment. This is often reinforced at university where introductory programming subjects' assessment consists of individual assignments (P. 148).

In many cases, computer related courses assign projects that lead to the students to work on projects individually with little requirement to interact with others (often termed individual projects). This is contrast to giving a project to a group of students where they divide responsibilities, work and complete the project together as a group (termed as a group project).

Numerous reasons lead to giving such individual projects as opposed to group projects. Among these reasons include the difficulty with evaluating the contribution of each student when assigning group projects.

This kind of continuous individual projects leads to students working alone for extended period of time. It helps with the evaluation process of the work completed by each student and helps also with assessing the learning criteria. This kind of project however does not give the students the experience of working together or collaborating with each other in order to achieve a common task. Thus, if this policy is followed for a long period of time during a semester, it may lead to creating a competitive environment among the students in the classroom. This kind of competitive environment of individual projects is often seen as one of the factors that lead some women to avoid computer programs all together or it leads them to drop out of the program once enrolled [5].

\section{SUGGESTED REMEDIES}

Numerous studies conducted to suggest remedies for the problem on decline in enrollment among women in technology program. At the same rate, different universities adopted policies and procedures to overcome this gap in enrollment. Some went to an extent and changed administrative procedures to make the program more adaptable to women.

In a study conducted by Cantwell [3] noted that while the number of women completing bachelor's degrees have increased, however the number of women completing computer science bachelor's degrees have not increased accordingly. This study done at Murray State University examined possible reasons for this gender gap by looking at data obtained from the Computer Programming SelfEfficacy Scale and a questionnaire developed for an introductory college computer science course. It attempted to determine the differences between genders, and then determine the factors that promote success. The findings indicate that an environment which encourages students to ask and answer questions both in class and outside of class helps female students to feel comfortable and not intimidated.

Dean [5] reported that Carnegie Mellon University moved away from emphasizing programming proficiency and now look for applicants who are high overall achievers with broad interests, diverse perspectives and potential future leaders. With the changes they have made, women are now 40 percent of the computer science enrollees which is up 8 percent from prior years.

Other programs changed their requirements regarding admission into computer programs by eliminating the math requirement to give women a better chance for being admitted into computer programs. 
Although the suggestions to improve women's enrollment are numerous; but certain factors can be emphasized from pedagogical perspectives to attract and improve the retention of women in technology programs. The remainder of this section elaborates on some of the pedagogical tools that helps improve women's perception of computer programs.

\section{Beginner Programming language}

The core of concerns regarding women's enrollment has to do with learning to program especially at entry level or beginner programming courses. Women most often tend to view it as difficult, boring, time consuming and others.

Since this is a problem facing new programming courses, a number of programming languages have been developed to alleviate this problem. This group of languages is intended to make it simpler to understand the concepts of programming languages. It helps also in dealing with the issue of syntax, structure and it cuts down from the time it takes to develop a program. Additionally, these programming languages produce output that are engaging and have characters that women relate to more often. Example of this is Alice Programming language that is named after the movie character "Alice and the Wonderland) which most often women relate to it [5] [7].

\section{Collaborative learning}

Collaborative learning is a term that used in academia to reflect two or more students work on the same project to complete certain tasks. The division of the work in this approach may be done according to certain criteria; however, the ultimate objective is to have students work together on completing specific projects. Another term used in computer to denote the same concept of collaborative learning which is called "Pair Programming" or "Collaborative Programming" [12].

McDowell eta al. [11] conducted a study at the University of California to examine collaborative programming as a computer software development approach. This method requires two programmers to work simultaneously on the same design, where one actively creates code and the other reviews the data. The roles are then reversed and the individuals complete the same task taking different roles. This method was successful and led to increase the Volume X, No. 1, 2009 number of both women and men that persisted in their quest for a computer science degree. The conclusion of this study strongly suggests that pair programming is an effective pedagogical tool. It increases the course completion rates and the persistence of students in computer science-related majors. The pairing also produced higher quality programs and more confidence and enjoyment in the computer programming work. This is one strategy to help foster women's interest and promote success in computer science, and the research indicates it should also be investigated in the workplace as well [11].

In a study conducted by Teague and Roe [13] found that although students have difficulty understanding programming concepts in beginner programming courses. However, the same students also believed that collaborative learning would have a beneficial impact on their learning outcomes and make studying programming more engaging, interactive, and fun.

\section{Addressing the Social Issue}

Giving projects that engage the students and make them work together may help address the social issue of attending computer programs. A successful policy helped in the past is to use service learning project in technology courses [10]. By service learning project, we mean involving the students to engage with community based organizations that they provide service to the organization and in return the organizations provide them with practical experience. This service learning project policy was proven to be helpful especially to the perception of women about computer technology projects [10].

\section{THE TST PROGRAM AT IUP}

The Technology Support and Training (TST) department at Eberly College of Business in Indiana University of Pennsylvania (IUP) offers two bachelor degrees, a master degree and an associate degree. The associate degree is in Business, Computer and Information Technology. The two bachelor degrees are first in Business Education and second in Business Technology
Issues in Information Systems 
Support. The same department offers a master degree program in Business Education (M.Ed.). The main goal of this master degree is to prepare students to be teachers in the business and technology field.

This department tries to stay away from programming courses as much as possible. However, in the graduate program of M.Ed, there is one course called BTST680 Technical Update. In this course, programming is taught as part other latest technology update topics. This section elaborates on a successful experience of the course in having a higher level of satisfaction among women who have taken this course. This higher level of satisfaction is attributed mainly to two factors: first choosing a beginner level programming language to teach in this course, and second adopting the collaborative learning (Pair Programming) approach to complete programming projects.

\section{Beginner programming languages:}

This course teaches Alice programming language. This language is notorious for simplifying the learning of programming concepts and eliminates a lot of the problems that are associated with syntax and learning the structure of programming. This language also has many characters that attract women into learning to program, like Alice and the Wonderland, The Ice skater and other character that interest women more [7].

The BTST680 course begins by showing a video and elaborating on the success stories and the applications that are developed using Alice. This introduction seems to succeed in attracting the attention of female students in the class. So that leads to a good start.

A number of different projects are given in this course in Alice. All the projects engage the students in the output and make the students interact with the program, thus making a dynamic learning environment. Women in particular were pleased by the simplicity that Alice approaches the different concepts. The female students were more pleased about the programs that were given since it involves character that they relate to, like snowman, ice skater and firefighter.

\section{Collaborative Learning}

Volume X, No. 1, 2009
Pair programming is used in this course. The examples assigned in the course start by giving the students individual assignments. These assignments are often instructor led tutorials that shows the different functionality of Alice and their application. After completing the instructor led (or the individual assignment), the class is divided into groups of two students so they work on larger projects. The groups are divided according to their background where the students with the most experience are paired with the students that have least experience.

Both strategies were successful in the course and the female students reported a large degree of satisfaction with learning the principles of programming. At the same time, enrollment in this course increased each of the past two years that the professor taught this course.

\section{SUMMARY AND FUTURE PLAN}

This paper wrote about the decline of women's enrollment in technology courses and the efforts that were devoted to reverse this trend and gain larger degree of satisfaction from women enrolled in technology courses. The paper began by explaining the magnitude of the problem in terms of numbers and also from trend perspectives. It then discussed the factors that led to this decline of women's enrollment in technology courses and suggested remedies for this decline. The paper then elaborated on the experience of the Technology Support and Training (TST) department at Indiana University of Pennsylvania (IUP) and their BTST680 Technical Update course. The course was successful in increasing enrollment and attracting more women into their course and also gained a larger degree of satisfaction regarding programming concepts and their application.

Working on this paper showed that the trend of decline in women's enrollment in technology program can be reversed. It showed from theoretical aspect that some of the obstacles that prevent women from applying into computer programs can be dealt with. However, there is no hard or empirical data to support the finding. The 230

Issues in Information Systems 
intention of the author of this paper is conduct another study where data about enrollment trend can be show at Indiana University of Pennsylvania. It also intends to survey the students regarding their satisfaction of the tools used in the courses. Furthermore, the intended paper plans to combine data from other programs at Indiana University of Pennsylvania (like data from the computer science department), to see if a comprehensive policy can be drawn to deal with this issue of decline enrollment among women in technology related programs.

\section{REFERENCES}

1. Ali, A.; Mensch, S. (2008) Issues and Challenges for Selecting a Programming Language in a Technology Update Course. Proceedings of the Information Systems Education Conference: Phoenix, AZ 2008 retrieved November 17, 2008 from. http://isedj.org/isecon/2008/020/index.html

2. Blum, L., \& Frieze, C. (2005). The Evolving Culture of Computing. Frontiers: A Journal of Women Studies, 26(1), 110-125. Retrieved June 11, 2008, from Academic Search Complete database.

3. Cantwell Wilson, B. (2002, March). A Study of Factors Promoting Success in Computer Science Including Gender Differences. Computer Science Education, 12(1/2), 141. Retrieved June 11, 2008, from Academic Search complete database.

4. Carter, J.; Jenkins, T. (2002). Gender differences in programming?. Proceedings of the 7th annual conference on Innovation and technology in computer science education, Retrieved April 15, 2008 from ACM Digital Library http://www.acm.org/dl

5. Dann, W.; Copper, S. \& Pausch, R. (2006). Learning to Program with Alice. Upper Saddle River, NJ: Prentice Hall.

6. Dean, C. (2007, April 17). Computer Science Takes Steps To Bring Women to the Fold. New York Times, Retrieved June 12, 2008, from Academic Search Complete database

7. Herbert, Charles (2007). An Introduction to Programming with Alice. Boston, Massachusetts: Course Technology.
8. Kelleher, C; Pausch, Randy (2005) Lowering the Barriers to Programming: A Taxonomy of Programming Environment and Languages for Novice Programmers. ACM Computing Surveys 37(2), 83-137. Retrieved March 28, 2008 from ACM Digital Library http://www.acm.org/dl.

9. Lenox, L. L.; Woratschek, C. C; Davis, G, A (2008). Exploring Declining CS/IS/IT Enrollments. Informatin Systems Education Journal, 6(44), 1-11.

10. Liu, C. (2005). Enriching Software Engineering Courses with Service Learning Projects and the Open-Source Approach. Proceedings of the 27th international conference on Software engineering, 613-614. Retrieved March 8, 2009 from ACM digital library http://www.acm.org/dl.

11. McDowell, C; Werner, L; Bullock, H; Fernald, Julian (2006). Communication of the ACM, 49 (2), 90-95. Retrieved March 7, 2009 from ACM digital library http://www.acm.org/dl.

12. Simon, B.; Hanks, B. (2006) Pair programming improves student retention, confidence, and program quality. Communications of the ACM, 49 (8), 1-28.

13. Teague, D.; Roe. R. (2008). Collaborative Learning - towards a solution for novice programmers. Proceedings of the tenth conference on Australasian computing education - Volume 78 , 147-153.

14. Varma, R. (2007). Decoding the Female Exodus from Computing Education, Information, Communication \& Society, 10(2), 181-193. Retrieved June 12, 2008 from Academic Search Complete database.

15. Vilner, T.; Zur, E. (2006).Once She Makes it There: Gender Differences in Computer Science Study. ITICSE '06: Proceedings of the 11th annual SIGCSE conference on Innovation and technology in computer science education. Retrieved March 6, 2009 from ACM digital library http://www.acm.org/dl. 